\title{
Characteristics and Predictors of Progression Interstitial Lung Disease in Rheumatoid Arthritis Compared with Other Autoimmune Disease: A Retrospective Cohort Study
}

\author{
Natalia Mena-Vázquez 1,2,*(1), Marta Rojas-Gimenez ${ }^{3,4}$ (), Carmen María Romero-Barco ${ }^{1,5}$, \\ Sara Manrique-Arija ${ }^{1,2}{ }^{\circ}$, Ana Hidalgo Conde ${ }^{6}$, Rocío Arnedo Díez de los Ríos ${ }^{6}$, Eva Cabrera César ${ }^{7}$, \\ Rafaela Ortega-Castro ${ }^{3,4}$, Francisco Espildora ${ }^{8}$, María Carmen Aguilar-Hurtado ${ }^{9}$, Isabel Añón-Oñate ${ }^{10}(0$, \\ Lorena Pérez-Albaladejo ${ }^{11}$, Manuel Abarca-Costalago ${ }^{6}$, Inmaculada Ureña-Garnica ${ }^{1,2} \mathbb{D}$, \\ Maria Luisa Velloso-Feijoo ${ }^{12}$, Rocio Redondo-Rodriguez ${ }^{1,2}$ and Antonio Fernández-Nebro ${ }^{1,2,13}$
}

check for

updates

Citation: Mena-Vázquez, N.;

Rojas-Gimenez, M.;

Romero-Barco, C.M.;

Manrique-Arija, S.;

Hidalgo Conde, A.;

Arnedo Díez de los Ríos, R.;

Cabrera César, E.; Ortega-Castro, R.;

Espildora, F.;

Aguilar-Hurtado, M.C.; et al.

Characteristics and Predictors of

Progression Interstitial Lung Disease

in Rheumatoid Arthritis Compared

with Other Autoimmune Disease: A

Retrospective Cohort Study.

Diagnostics 2021, 11, 1794. https:/ /

doi.org/10.3390/diagnostics11101794

Academic Editor: Xavier Bosch

Received: 2 August 2021

Accepted: 27 September 2021

Published: 28 September 2021

Publisher's Note: MDPI stays neutral with regard to jurisdictional claims in published maps and institutional affiliations.

Copyright: (c) 2021 by the authors. Licensee MDPI, Basel, Switzerland. This article is an open access article distributed under the terms and conditions of the Creative Commons Attribution (CC BY) license (https:// creativecommons.org/licenses/by/ $4.0 /)$.
1 Instituto de Investigación Biomédica de Málaga (IBIMA), 29010 Málaga, Spain; menchu01@hotmail.com (C.M.R.-B.); sarama_82@hotmail.com (S.M.-A.); inuregar@gmail.com (I.U.-G.); rocioredondo91@hotmail.com (R.R.-R.); afnebro@gmail.com (A.F.-N.)

2 UGC de Reumatología, Hospital Regional Universitario de Málaga, 29009 Málaga, Spain

3 Instituto Maimónides de Investigación Biomédica de Córdoba (IMIBIC), 14004 Córdoba, Spain; rojasgimenezm@gmail.com (M.R.-G.); orcam84@hotmail.com (R.O.-C.)

4 UGC de Reumatología, Hospital Universitario Reina Sofía de Córdoba, 14004 Córdoba, Spain

5 UGC de Reumatología, Hospital Clínico Universitario Virgen de la Victoria, 29010 Málaga, Spain

6 Servicio de Medicina Interna, Hospital Universitario Virgen de la Victoria, 29010 Málaga, Spain; ahidalgoconde@gmail.com (A.H.C.); rocioardiez@gmail.com (R.A.D.d.1.R.); maabco@gmail.com (M.A.-C.)

7 UGC Neumología, Hospital Universitario Virgen de la Victoria, 29010 Málaga, Spain; evacabreracesar@gmail.com

8 UGC de Neumología, Hospital Regional Universitario de Málaga, 29009 Málaga, Spain; fespildorahernandez@gmail.com

9 UGC de Radiodiagnóstico, Hospital Regional Universitario de Málaga, 29009 Málaga, Spain; maguh007@gmail.com

10 Hospital Universitario de Jaén, 23007 Jaén, Spain; isaanononate@gmail.com

11 Hospital Universitario Virgen de las Nieves, 18170 Granada, Spain; lorenaperezalba@gmail.com

12 Hospital Universitario Virgen de Valme, 41014 Sevilla, Spain; mlvelloso@hotmail.com

13 Departamento de Medicina, Universidad de Málaga, 29010 Málaga, Spain

* Correspondence: nataliamenavazquez@gmail.com; Tel.: +34-952290360

Abstract: Objectives: To describe the characteristics and progression of interstitial lung disease in patients with associated systemic autoimmune disease (ILD-SAI) and to identify factors associated with progression and mortality. Patients and methods: We performed a multicenter, retrospective, observational study of patients with ILD-SAI followed between 2015 and 2020. We collected clinical data and performed pulmonary function testing and high-resolution computed tomography at diagnosis and the final visit. The main outcome measure at the end of follow-up was forced vital capacity (FVC) $>10 \%$ or diffusing capacity of the lungs for carbon monoxide $>15 \%$ and radiological progression or death. Cox regression analysis was performed to identify factors associated with worsening of ILD. Results: We included 204 patients with ILD-SAI: 123 (60.3\%) had rheumatoid arthritis (RA), 58 had (28.4\%) systemic sclerosis, and $23(11.3 \%)$ had inflammatory myopathy. After a median (IQR) period of 56 (29.8-93.3) months, lung disease had stabilized in 98 patients (48\%), improved in 33 (16.1\%), and worsened in $44(21.5 \%)$. A total of 29 patients $(14.2 \%)$ died. Progression and hospitalization were more frequent in patients with RA $(p=0.010)$. The multivariate analysis showed the independent predictors for worsening of ILD-SAI to be RA (HR, 1.9 [95\% CI, 1.3-2.7]), usual interstitial pneumonia pattern (HR, 1.7 [95\% CI, 1.0-2.9]), FVC (\%) (HR, 2.3 [95\% CI, 1.4-3.9]), and smoking (HR, 2.7 [95\%CI, 1.6-4.7]). Conclusion: Disease stabilizes or improves after a median of 5 years in more than half of patients with ILD-SAI, although more than one-third die. Data on subgroups and risk factors could help us to predict poorer outcomes.

Keywords: rheumatoid arthritis; systemic autoimmune disease; interstitial lung disease; prognosis 


\section{Introduction}

Interstitial lung disease (ILD) is a common condition in patients with systemic autoimmune diseases (SAIs) that is characterized by increased morbidity and mortality [1]. The SAIs most associated with ILD (ILD-SAI) include systemic sclerosis (SS), rheumatoid arthritis (RA), and inflammatory myopathy (IM). These conditions are reported to affect up to $70 \%$ of patients with ILD [2]. The most frequent subtype of ILD in high-resolution computed tomography (HRCT) and histopathology is nonspecific interstitial pneumonia (NSIP), except in RA, where the most frequent subtype is usual interstitial pneumonia (UIP) [3].

ILD is the main cause of death in patients with SS and IM [3-5], whereas in RA, it is the second cause of death after cardiovascular disease [1]. Furthermore, the percentage of patients who experience progression of ILD in all these diseases is variable [4-6]. Some studies have tried to identify factors that can help us to predict a poorer prognosis and/or greater mortality in patients with ILD-SAI. Poorer prognosis of ILD-SAI has been associated with demographic factors, such as advanced age [7-12], male sex $[8,10,13,14]$, and history of smoking [2,15]. Similarly, reduced forced vital capacity (FVC) and diffusing capacity of the lung for carbon monoxide (DLCO) [15-17] and the UIP radiological pattern in HRCT have also been associated with marked progression and mortality in the different types of ILD-SAI [5,12,18-26]. The most common drugs for treatment of this condition include corticosteroids, cyclophosphamide, mycophenolate mofetil, and azathioprine [2]. Similarly, antifibrotic agents, such as nintedanib, could have a beneficial effect on the lungs of affected patients, as shown by the studies SENSCIS [27] and INBUILD [28]. In recent years, treatment with the immunosuppressants rituximab and abatacept has been reported to be safe and effective in ILD-SAI [29-35].

Knowledge of the factors associated with progression and mortality of ILD-SAI is important for identifying patients who may require more intensive therapy or earlier referral for evaluation of lung transplant. However, it is also interesting to identify epidemiologic and clinical differences, as well as differences in how progress of the various types of ILD-SAI affects the lungs, since this will provide a better picture of the progress of each group of patients and make it possible to identify more susceptible groups. However, few studies have compared the epidemiological, clinical, and progression-related characteristics of ILD-SAI using HRCT and pulmonary function testing (PFT). Therefore, the objectives of our study were as follows: (1) to describe the clinical and epidemiological characteristics of patients with ILD-SAI; (2) to compare the progression of lung disease and mortality in the various types of ILD-SAI; and (3) to identify factors associated with progression and mortality in patients with ILD-SAI.

\section{Materials and Methods}

\subsection{Design}

We performed a multicenter retrospective observational study of a cohort of patients with ILD-SAI from 6 teaching hospitals in Andalusia, Spain. The study was approved by the Research Ethics Committee of Hospital Regional Universitario de Málaga (HRUM), Malaga, Spain (Código 2017-N-19). All the participants gave their written informed consent for their personal information to be included in the database.

\subsection{Study Population}

The study population comprised all patients with ILD-SAI in follow-up at the rheumatology clinic between January 2015 and December 2020. ILD was confirmed by PFT and HRCT or lung biopsy. The eligibility criteria were as follows: age $\geq 18$ years, RA classified according to the ACR/EULAR 2010 criteria [36], SS according to the ACR/EULAR 2013 criteria, and dermatomyositis and polymyositis (IM) according to the criteria of Bohan and Peter $[37,38]$, as applicable. Patients with an inflammatory or rheumatic disease other than RA, SS, or IM were excluded (except for secondary Sjögren syndrome). 


\subsection{Protocol}

Patients were seen every 3-6 months in the rheumatology clinic and every 6-12 months in the pulmonology clinic. They also systematically underwent HRCT and PFT at diagnosis of ILD (V0), at any other visit if they presented symptoms of respiratory impairment or if their physician considered these investigations necessary, and during 2019-2020 to determine lung progression data on the inclusion date (Vf). All HRCT scans were based on axial slices measuring 1.5 or $2 \mathrm{~mm}$ in thickness at $1-\mathrm{cm}$ intervals along the thorax and reconstructed using a high-spatial-frequency algorithm, with acquisition of 20-25 slices per patient. The radiological evaluation was centralized at HRUM and performed blind and independently by 2 experts in pulmonary radiology. Discrepancies between the readings were resolved by mutual agreement. Data were collected at V0 and Vf.

\subsection{Working Definitions and Variables}

The main variable was "Course of ILD at the end of follow-up (Vf)" with respect to the following: (1) improvement (i.e., improvement in FVC $\geq 10 \%$ or DLCO $\geq 15 \%$ and no radiological progression); (2) nonprogression (stabilization or improvement in FVC $\leq 10 \%$ or DLCO $<15 \%$ and no radiological progression); (3) progression (worsening of FVC $>10 \%$ or DLCO $>15 \%$ and radiological progression); or (4) death [31]. Radiological progression was defined as a $\geq 20 \%$ increase in the presence and extension of ground-glass opacities, reticulation, honeycombing, diminished attenuation, centrilobular nodules, other nodules, emphysema, or consolidation compared with the HRCT images acquired at inclusion.

The different ILD patterns were defined according to the lung biopsy or HRCT based on the standard criteria of the American Thoracic Society/European Respiratory Society International Multidisciplinary Consensus Classification of the Idiopathic Interstitial Pneumonias [39]. The 3 patterns defined were as follows: nonspecific interstitial pneumonia (NSIP), usual interstitial pneumonia (UIP), and other (bronchiolitis obliterans [BO], organizing pneumonia [OP], lymphoid pneumonitis, and mixed patterns). PFT included full spirometry expressed as percent predicted and corrected for age, sex, and height. An FVC value $<80 \%$ predicted was considered abnormal. DLCO was evaluated using the single-breath technique (DLCO-SB) and was considered abnormal at DLCO-SB $<80 \%$.

Other variables included time with symptoms, diagnostic delay, smoking history (current or previous), and co-occurrence of Sjögren syndrome. We recorded the infections in the clinical history, as well as the clinical event hospitalization and its causes. We also recorded laboratory variables, such as autoantibodies, rheumatoid factor (RF, reference, $20 \mathrm{U} / \mathrm{mL}$; high titer $>60 \mathrm{U} / \mathrm{mL}$ ), anticitrullinated peptide antibody (ACPA) (reference, $10 \mathrm{U} / \mathrm{mL}$; high values $>340 \mathrm{U} / \mathrm{mL}$ ), antinuclear antibody (ANA), anti-U1RNP (MCTD), anti-Scl70, anti-RNA polymerase III, anti-PM-Scl (PM-Scl overlap), anti-Ro $52 \mathrm{kDa}$, anti-Ro $60 \mathrm{kDa}$, anti-La, anti-aminoacyl-tRNA synthetase, anti-Mi-2, anti-SRP, anti-TIF1, anti-NXP-2/MJ, anti-MDA5 (CADM), anti-HMGCR, and anti-SAE. We recorded treatment with conventional synthetic disease-modifying antirheumatic drugs (csDMARDs), targeted synthetic DMARDs (tsDMARDs), biologic DMARDs (bDMARDs), immunosuppressants, and antifibrotic drugs, as well as corticosteroids.

\subsection{Statistical Analysis}

A descriptive analysis was made of the clinical, epidemiological, and autoimmune characteristics and the treatment they received. Qualitative variables were expressed as absolute number and percentage and qualitative variables as mean and standard deviation (SD) or median and interquartile range (IQR), depending on the normality of the distribution, as assessed using the Kolmogorov-Smirnov test. A $\chi 2$ or ANOVA test or Kruskal-Wallis test was performed (as applicable) to compare the main characteristics between the 3 groups of patients: (1) patients with ILD-RA; (2) patients with ILD-SS; and (3) patients with ILD-IM. The bivariate analysis was performed using a paired $t$ test or Wilcoxon test, as applicable, between V0 and the end of follow-up. Kaplan-Meier curves and the log-rank test were used to estimate the survival of patients with ILD-SAI and to 
compare survival between the 3 groups of patients. Survival was measured from diagnosis of ILD to the end of the inclusion period (Vf) or death. Cox regression analysis was used to identify prognostic factors for time to progression or death using univariate and multivariate analysis (forward stepwise). All variables for which $p<0.10$ were included in the Cox multivariate analysis. The incidence of all, severe, and mild adverse events was analyzed. The analysis was performed using $\mathrm{R}$ Commander.

\section{Results}

\subsection{Clinical and Epidemiological Characteristics}

The study population comprised 204 patients with ILD-SAI, of whom $123(60.3 \%)$ had RA, $58(28.4 \%)$ had SS, and $23(11.3 \%)$ had IM.

After a median (IQR) follow-up of 56 (29.8-93.3) months in patients with ILD, 175/204 $(85.7 \%)$ remained in follow-up, that is, 615.5 patient-years for RA, 462.4 patient-years for SS, and 255.9 patient-years for IM. A total of $29 / 204$ patients $(14.2 \%)$ died. The mean (SD) survival from diagnosis to death was 242.3 (13.3) months. No significant differences in survival were recorded between RA, SS, and IM (mean [95\% CI], 184.4 months [17.1] vs. 200.3 months [20.6] vs. 267.0 (16.4) months; $p=0.469$ [log-rank test]).

The main baseline characteristics for the overall sample and the 3 subgroups are shown in Table 1. The three groups differed in terms of epidemiologic, clinical, and laboratory characteristics, as well as in the treatment they received. Women accounted for more than half of the patients with ILD-SAI (66\%). The mean age was 65 years, and almost half of the patients had been smokers or were smokers at inclusion. Compared with the other groups, patients with RA were more equally balanced in terms of sex, had a higher mean age, and were more frequently smokers or former smokers. Similarly, the three groups differed with respect to the specificity of antibodies and treatment. More than $80 \%$ of patients with RA were RF- or ACPA-positive, whereas those with SS more frequently had a positive anti-scl70 titer (48\%), followed by a positive anticentromere titer (34\%). The most frequent antibodies in IM were anti-Jo (26\%) and PL-7 (21\%).

Table 1. Clinical-epidemiologic characteristics.

\begin{tabular}{|c|c|c|c|c|c|}
\hline & $\begin{array}{c}\text { Total } \\
(\mathrm{n}=204)\end{array}$ & $\begin{array}{c}\text { RA } \\
(n=123)\end{array}$ & $\begin{array}{c}\text { IM } \\
(n=23)\end{array}$ & $\begin{array}{c}\text { SS } \\
(n=58)\end{array}$ & $p$ Value \\
\hline \multicolumn{6}{|l|}{ Epidemiological characteristics } \\
\hline Female sex, $\mathrm{n}(\%)$ & $136(66.7)$ & $67(54.5)$ & $18(78.3)$ & $51(87.9)$ & $<0.001$ \\
\hline Caucasian race, $\mathrm{n}(\%)$ & $198(97.1)$ & $119(96.7)$ & $23(100)$ & $56(96.6)$ & 0.673 \\
\hline Age, years, mean (SD) & $65.3(12.6)$ & $69.2(9.6)$ & $55.5(18.5)$ & $61.0(12.2)$ & $<0.001$ \\
\hline \multicolumn{6}{|l|}{ Clinical and laboratory characteristics } \\
\hline Smoking & & & & & 0.002 \\
\hline Nonsmokers, n (\%) & $112(54.9)$ & $54(43.9)$ & $19(82.6)$ & $39(67.2)$ & \\
\hline Smokers, n (\%) & $36(17.6)$ & $28(22.8)$ & $1(4.3)$ & $7(12.1)$ & \\
\hline Exsmokers, n (\%) & $56(27.5)$ & $41(33.3)$ & $3(13.0)$ & $12(20.7)$ & \\
\hline Time with SAI, months, median (IQR) & $124.0(57.4-209.7)$ & $146.3(68.2-218.1)$ & $51.7(25.1-157.5)$ & $119.3(56.6-206.1)$ & 0.037 \\
\hline Time with ILD, months, median (IQR) & $56.5(29.8-93.3)$ & $51.8(28.5-85.9)$ & $33.9(25.1-80.5)$ & $65.5(40.3-140.1)$ & 0.059 \\
\hline RF-positive $(>10), \mathrm{n}(\%)$ & $122(59.8)$ & $119(96.7)$ & $1(4.3)$ & $2(3.4)$ & $<0.001$ \\
\hline ACPA $(>20), n(\%)$ & $107(52.5)$ & $107(87.0)$ & $0(0.0)$ & $0(0.0)$ & $<0.001$ \\
\hline ANA-positive, n (\%) & $104(51.0)$ & $30(24.6)$ & $19(82.6)$ & $55(94.8)$ & $<0.001$ \\
\hline Anti-SCL70, n (\%) & $28(13.8)$ & $0(0.0)$ & $0(0.0)$ & $28(48.3)$ & $<0.001$ \\
\hline Anticentromere, n (5) & $20(9.8)$ & $0(0.0)$ & $0(0.0)$ & $20(34.4)$ & $<0.001$ \\
\hline PM-SCL, n (\%) & $3(1.5)$ & $0(0.0)$ & $0(0.0)$ & $3(5.1)$ & 0.033 \\
\hline RNP, n (\%) & $2(1.0)$ & $0(0.0)$ & $0(0.0)$ & $2(3.4)$ & 0.079 \\
\hline Anti-Ku, n (\%) & $1(0.5)$ & $0(0.0)$ & $0(0.0)$ & $2(3.4)$ & 0.079 \\
\hline RNA-polymerase 3, n (\%) & $1(0.5)$ & $0(0.0)$ & $0(0.0)$ & $1(1.7)$ & 0.282 \\
\hline Anti-Jo, n (\%) & $6(2.9)$ & $0(0.0)$ & $6(26.1)$ & $0(0.0)$ & $<0.001$ \\
\hline Anti-PL7, n (\%) & $5(2.5)$ & $0(0.0)$ & $5(21.7)$ & $0(0.0)$ & $<0.001$ \\
\hline Anti-EJ, n (\%) & $1(0.5)$ & $0(0.0)$ & $1(4.3)$ & $0(0.0)$ & 0.019 \\
\hline Anti-NMDA, n (\%) & $3(1.5)$ & $0(0.0)$ & $3(13.0)$ & $0(0.0)$ & $<0.001$ \\
\hline Anti-TIF, n (\%) & $2(1.0)$ & $0(0.0)$ & $2(8.7)$ & $0(0.0)$ & $<0.001$ \\
\hline Anti-SRP, n (\%) & $1(0.5)$ & $0(0.0)$ & $1(4.3)$ & $0(0.0)$ & 0.019 \\
\hline Secondary Sjögren syndrome, n (\%) & $33(16.2)$ & $18(14.6)$ & $6(26.1)$ & $9(15.5)$ & 0.387 \\
\hline Treatment & & & & & \\
\hline Conventional synthetic DMARDs, n (\%) & $129(63.5)$ & $105(85.4)$ & $12(52.2)$ & $12(20.7)$ & $<0.001$ \\
\hline Methotrexate, n (\%) & $62(30.4)$ & $53(43.1)$ & $4(17.4)$ & $5(8.6)$ & $<0.001$ \\
\hline Leflunomide, n (\%) & $32(15.7)$ & $31(25.2)$ & $0(0.0)$ & $1(1.7)$ & $<0.001$ \\
\hline Sulfasalazine, n (\%) & $9(4.4)$ & $9(7.3)$ & $0(0.0)$ & $0(0.0)$ & $<0.001$ \\
\hline
\end{tabular}


Table 1. Cont.

\begin{tabular}{|c|c|c|c|c|c|}
\hline & $\begin{array}{c}\text { Total } \\
(\mathrm{n}=204)\end{array}$ & $\begin{array}{c}\text { RA } \\
(n=123)\end{array}$ & $\begin{array}{c}\text { IM } \\
(n=23)\end{array}$ & $\begin{array}{c}\text { SS } \\
(n=58)\end{array}$ & $p$ Value \\
\hline Hydroxychloroquine, n (\%) & $36(17.7)$ & $23(18.7)$ & $8(34.7)$ & $5(8.6)$ & 0.016 \\
\hline Biologic DMARDs, n (\%) & $78(38.2)$ & $57(46.3)$ & $6(26.1)$ & $15(25.9)$ & 0.013 \\
\hline Anti-TNF, n (\%) & $14(6.9)$ & $14(11.4)$ & $0(0.0)$ & $0(0.0)$ & 0.343 \\
\hline Tocilizumab, n (\%) & $8(6.9)$ & $5(4.1)$ & $1(4.3)$ & $2(3.4)$ & 0.343 \\
\hline Abatacept, n (\%) & $19(9.3)$ & 19 (15.4) & $0(0.0)$ & $0(0.0)$ & 0.001 \\
\hline Rituximab, n (\%) & $37(18.1)$ & $19(15.4)$ & $4(17.4)$ & $14(24.1)$ & 0.365 \\
\hline Immunosuppressants & $75(36.9)$ & $15(12.2)$ & $20(87.0)$ & $40(68.9)$ & $<0.001$ \\
\hline Mycophenolate, n (\%) & $58(28.5)$ & $10(8.1)$ & $13(56.5)$ & $35(60.3)$ & $<0.001$ \\
\hline Azathioprine, n (\%) & $14(6.9)$ & $5(4.1)$ & $6(26.1)$ & $3(5.1)$ & 0.009 \\
\hline Cyclophosphamide, n (\%) & $3(1.5)$ & $0(0.0)$ & $1(4.3)$ & $2(3.4)$ & 0.095 \\
\hline Antifibrotic drugs, nintedanib n (\%) & $4(2.0)$ & $2(1.6)$ & $0(0.0)$ & $2(3.4)$ & 0.549 \\
\hline Corticosteroids, $\mathrm{n}(\%)$ & $134(66.0)$ & $88(71.5)$ & $19(82.6)$ & $27(46.6)$ & 0.004 \\
\hline Dose of corticosteroids, median (IQR) & $5.0(0.0-7.5)$ & $5.0(0.0-7.5)$ & $5.0(5.0-10.0)$ & $2.5(0.0-5.0)$ & 0.003 \\
\hline
\end{tabular}

Abbreviations. RA: rheumatoid arthritis; IM: inflammatory myopathy; SS: systemic sclerosis; ILD: interstitial lung disease; RF: rheumatoid factor; ACPA: anticitrullinated protein antibodies; ANA: antinuclear antibodies, RNP: anti-U1RNP antibodies; DMARD: disease-modifying antirheumatic drug; SD: standard deviation. Statistical tests used: Pearson $\chi 2$, ANOVA, and Kruskal-Wallis.

All patients were receiving treatment for ILD at inclusion. More than half were taking csDMARDs (63\%), almost $40 \%$ were taking bDMARDs, $35 \%$ were taking immunosuppressants, and $2 \%$ were taking antifibrotics. Almost $70 \%$ of patients were receiving corticosteroids at a median dose of $5 \mathrm{mg} / \mathrm{d}$. Differences in treatment were observed between the subgroups, with mainly csDMARDs and bDMARDs in patients with RA and immunosuppressants in those with IM and SS. Rituximab was the most common bDMARD (37/204 patients [18.1\%]), although it was used more frequently in patients with SS (24\%) and IM (17\%) than in those with RA (15\%). Patients with SS took corticosteroids less frequently and at lower doses than the other subgroups.

The most common radiological pattern was NSIP $(99 / 204$ [48.5\%]) followed by UIP $(91 / 2014$ [44.6\%]), fibrotic NSIP (7/204 [3.4\%]), and other types of ILD (7/204 patients $[3.4 \%])$. By patient subgroup, NSIP was more common in patients with IM $(87 \%)$, and the UIP pattern was the most common in RA $(62 \%)$. While the NSIP pattern predominated in patients with SS $(72 \%)$, almost $30 \%$ had UIP or fibrotic NSIP $(p<0.001)$. Chest X-ray and high-resolution CT positive for different interstitial lung disease patterns in patients with ILD-SAI are shown in Figure 1.

A

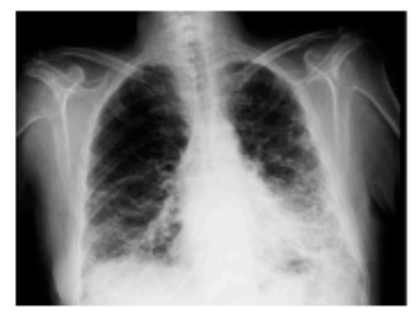

B

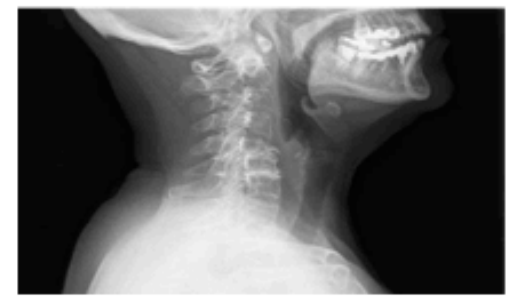

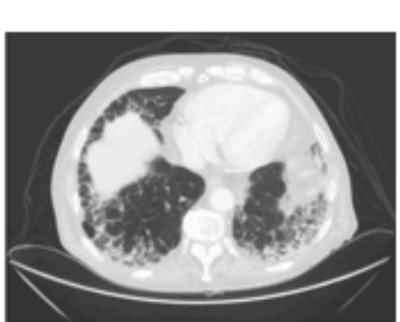

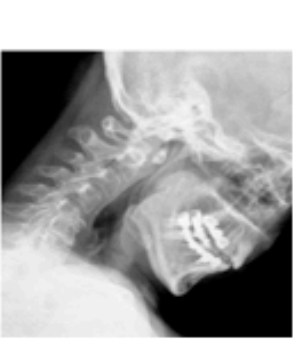

C

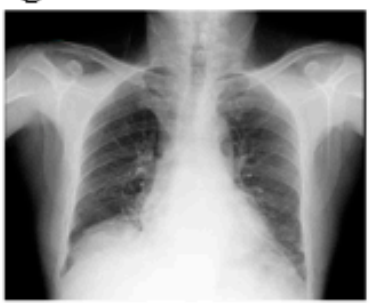

D

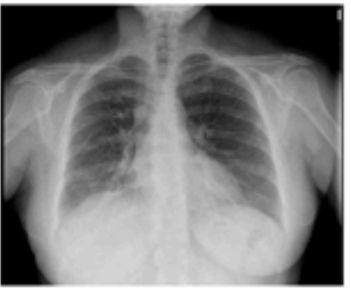

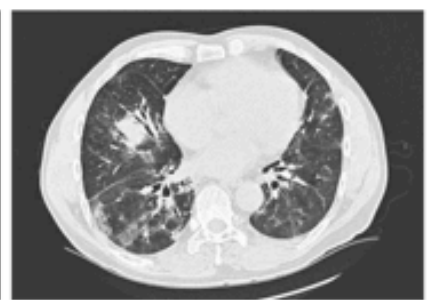

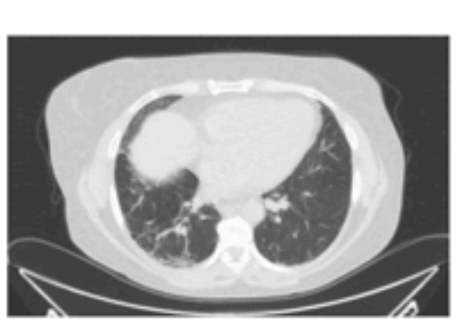

Figure 1. Chest X-ray and high-resolution CT positive for different interstitial lung disease patterns in patients with associated systemic autoimmune disease: (A) Pattern usual interstitial pneumonia (UIP) in a patient with rheumatoid arthritis. (B) Atlantoaxial subluxation in a patient with interstitial lung disease and rheumatoid arthritis. (C) Pattern nonspecific interstitial pneumonia (NSIP) in inflammatory myopathy. (D) Pattern nonspecific interstitial pneumonia (NSIP) in systemic sclerosis. 


\subsection{Clinical Course}

A total of 132/204 patients (64.7\%) developed an infection during follow-up. Most affected the respiratory tract (56.4\%), and 75/204 patients (36.8\%) were admitted to hospital at least once. The most common reason for hospitalization was respiratory infection (23.5\%), followed by progression of lung disease (10.3\%). No significant differences in respiratory infection were recorded between the different subgroups, whereas skin infections were more common in patients with SS (20.6\%) and IM (17.3\%) than in those with RA $(7.3 \%)$ $(p=0.032)$. Hospitalization was more common in RA $(44.7 \%)$, followed by SS $(27.6 \%)$ and IM $(17.4 \%)(p=0.010)$ (Table 2). Twenty-nine patients died $(14.2 \%)$ : 13 from progression of lung disease and superinfection, 10 from rapidly progressing ILD, and 6 from tumors and progression of lung disease.

Table 2. Clinical events.

\begin{tabular}{|c|c|c|c|c|c|}
\hline & $\begin{array}{c}\text { Total } \\
(\mathrm{n}=204)\end{array}$ & $\begin{array}{c}\text { RA } \\
(n=123)\end{array}$ & $\begin{array}{c}\text { IM } \\
(n=23)\end{array}$ & $\begin{array}{c}\text { SS } \\
(n=58)\end{array}$ & $p$ Value \\
\hline Infections, n (\%) & $132(64.7)$ & $82(66.7)$ & $15(65.2)$ & $35(60.3)$ & 0.666 \\
\hline Respiratory infection, $\mathrm{n}(\%)$ & $116(56.9)$ & $76(61.8)$ & $12(52.2)$ & $28(48.3)$ & 0.205 \\
\hline Other infections, $\mathrm{n}(\%)$ & $59(28.9)$ & $34(27.6)$ & $7(30.4)$ & $18(31.0)$ & 0.883 \\
\hline Cold sore (herpes), n (\%) & $10(4.9)$ & $7(5.6)$ & $1(4.3)$ & $2(3.4)$ & 0.242 \\
\hline Cutaneous, n (\%) & $25(12.2)$ & $9(7.3)$ & $4(17.3)$ & $12(20.6)$ & 0.032 \\
\hline Urinary infection, $\mathrm{n}(\%)$ & $28(13.7)$ & $19(15.4)$ & $3(13.0)$ & $6(10.3)$ & 0.460 \\
\hline Hospitalization, $\mathrm{n}(\%)$ & $75(36.8)$ & $55(44.7)$ & $4(17.4)$ & $16(27.6)$ & 0.010 \\
\hline Reason for hospitalization & & & & & 0.032 \\
\hline Respiratory infection, $\mathrm{n}(\%)$ & $48(23.5)$ & $37(30.1)$ & $4(17.4)$ & $7(12.1)$ & \\
\hline Progression of ILD, $\mathrm{n}(\%)$ & $21(10.3)$ & $15(12.2)$ & $0(0.0)$ & $6(10.3)$ & \\
\hline Other causes, $\mathrm{n}(\%)$ & $6(2.9)$ & $3(2.4)$ & $0(0.0)$ & $3(5.2)$ & \\
\hline Mortality, n (\%) & $29(14.2)$ & $19(15.4)$ & $1(4.3)$ & $9(15.5)$ & 0.355 \\
\hline
\end{tabular}

Abbreviations. ILD: interstitial lung disease; SAI: systemic autoimmune diseases; RA: rheumatoid arthritis; IM: inflammatory myopathy; SS: systemic sclerosis.

As for the main lung outcome at the end of follow-up (Table 3), most patients improved or stabilized and $36 \%$ worsened or died. By subgroup, progression or mortality was more frequent in patients with RA (48/123 [39\%]) than in those with SS $(21 / 58$ [36\%]) and $\operatorname{IM}(4 / 23[17 \%])(p=0.016)$. Mean survival until progression of lung disease or death was $136.3(11.0)$ months, with a median value that was greater for IM than for SS and RA (median [95\% CI], 171.7 [107.8-210.3] vs. 159.0 [137.9-174.7] vs. 111.3 [65.0-127.3] months; $p=0.017$ [log-rank]).

As shown in Table 3, mean PFT values worsened at the end of follow-up compared with baseline. By subgroup, FVC, FEV1, and DLCO decreased significantly at the end of follow-up in patients with RA, as did FVC and DLCO in patients with SS (Figure 2). Furthermore, as seen in the table, no significant differences in PFT values at diagnosis were recorded between the subgroups. However, at the end of follow-up, FVC and DLCO values were lower in patients with RA and SS than in those with IM $(p=0.036$ and $p=0.026$, respectively). 
Table 3. Results of pulmonary function testing.

\begin{tabular}{|c|c|c|c|c|c|c|}
\hline & & $\begin{array}{c}\text { Total } \\
(\mathrm{n}=\mathbf{2 0 4})\end{array}$ & $\begin{array}{c}\text { RA } \\
(n=123)\end{array}$ & $\begin{array}{c}\text { IM } \\
(n=23)\end{array}$ & $\begin{array}{c}\text { SS } \\
(n=58)\end{array}$ & $p$ Value \\
\hline \multicolumn{2}{|c|}{ Outcomes clinical course ${ }^{* *}$} & & & & & 0.016 \\
\hline Improvement, n (\%) & Final & $33(16.1)$ & $14(11.4)$ & $9(39.1)$ & $10(17.2)$ & \\
\hline Stabilization, $\mathrm{n}(\%)$ & Final & $98(48.0)$ & $61(49.5)$ & $10(43.5)$ & $27(46.6)$ & \\
\hline Worsening, $\mathrm{n}(\%)$ & Final & $44(21.5)$ & $29(23.5)$ & $3(13.0)$ & $12(20.7)$ & \\
\hline Death, n (\%) & Final & $29(14.2)$ & $19(15.4)$ & $1(4.3)$ & $9(15.5)$ & \\
\hline \multicolumn{7}{|c|}{ Pulmonary function testing } \\
\hline \multirow{2}{*}{ FVC, mean (SD) } & Baseline & $72.9(16.6)$ & $74.1(15.8)$ & $70.5(15.8)$ & $71.4(18.5)$ & 0.465 \\
\hline & Final & $68.2(16.2) *$ & $66.4(21.4) *$ & $72.3(15.8)$ & $67.5(22.8)$ * & 0.036 \\
\hline \multirow{2}{*}{$\mathrm{FVC}<80 \%, \mathrm{n}(\%)$} & Baseline & $119(58.3)$ & $73(60.9)$ & $11(49.8)$ & $35(60.3)$ & 0.772 \\
\hline & Final & $134(65.6)^{*}$ & $83(67.4)^{*}$ & $13(56.5)$ & $38(65.5) *$ & 0.045 \\
\hline \multirow{2}{*}{$\mathrm{FEV}_{1}$, mean $(\mathrm{SD})$} & Baseline & $77.7(16.2)$ & $78.8(16.2)$ & $72.0(15.5)$ & $75.5(15.9)$ & 0.168 \\
\hline & Final & $72.9(19.6) *$ & $71.9(20.4) *$ & $76.0(17.1)$ & $70.0(18.5)$ & 0.240 \\
\hline \multirow{2}{*}{ DLCO-SB, mean (SD) } & Baseline & $57.8(15.0)$ & $58.5(15.0)$ & $56.8(14.3)$ & $56.9(15.4)$ & 0.775 \\
\hline & Final & $53.8(16.4) *$ & $54.1(16.2) *$ & $60.5(15.1)$ & $51.8(16.5) *$ & 0.026 \\
\hline \multirow{2}{*}{\multicolumn{2}{|c|}{$\begin{array}{c}\text { HRCT pattern } \\
\text { Radiologic pattern }\end{array}$}} & & & & & \\
\hline & & & & & & $<0.001$ \\
\hline \multirow{2}{*}{ UIP, n (\%) } & Baseline & $86(42.1)$ & $74(60.1)$ & $2(8.7)$ & $10(17.2)$ & \\
\hline & Final & $91(44.6)$ & $77(62.6)$ & $2(8.7)$ & $15(25.8)$ & \\
\hline \multirow{2}{*}{ NSIP, n (\%) } & Baseline & $101(49.5)$ & $35(28.5)$ & $20(86.9)$ & $46(79.3)$ & \\
\hline & Final & $99(48.5)$ & $33(26.8)$ & $20(86.9)$ & $42(72.4)$ & \\
\hline \multirow{2}{*}{ Fibrotic NSIP, n (\%) } & Baseline & $10(4.9)$ & $7(5.6)$ & $1(4.3)$ & $2(3.4)$ & \\
\hline & Final & $7(3.4)$ & $6(4.8)$ & $1(4.3)$ & $1(3.4)$ & \\
\hline \multirow{2}{*}{ Other types, n (\%) } & Baseline & $7(3.4)$ & $7(5.6)$ & $0(0.0)$ & $0(0.0)$ & \\
\hline & Final & $7(3.4)$ & $7(5.6)$ & $0(0.0)$ & $0(0.0)$ & \\
\hline \multicolumn{2}{|c|}{ Progression by HRCT } & & & & & 0.002 \\
\hline Progression, $\mathrm{n}(\%)$ & Final & $72(35.3)$ & $48(39.0)$ & $4(17.4)$ & $20(34.5)$ & \\
\hline Stabilization, n (\%) & Final & $93(45.6)$ & $60(48.8)$ & $7(30.4)$ & $26(44.8)$ & \\
\hline Improvement, n (\%) & Final & $39(19.1)$ & $15(12.2)$ & $12(52.2)$ & $12(20.7)$ & \\
\hline
\end{tabular}

Abbreviations. RA: rheumatoid arthritis; IM: inflammatory myopathy; SS: systemic sclerosis; ILD: interstitial lung disease; FVC: forced vital capacity; FEV1: forced expiratory volume in the first second; DLCO: diffusing capacity of the lung for carbon monoxide; UIP: usual interstitial pneumonia; NINE: nonspecific interstitial pneumonia; HCRT: high-resolution computed tomography; ${ }^{*} p<0.005$ final vs. baseline; ** Total progression of lung disease: based on HRCT and PFT (FVC and DLCO). Statistical tests used: Pearson $\chi 2$, ANOVA, Kruskal-Wallis, paired $\mathrm{t}$, and Wilcoxon.

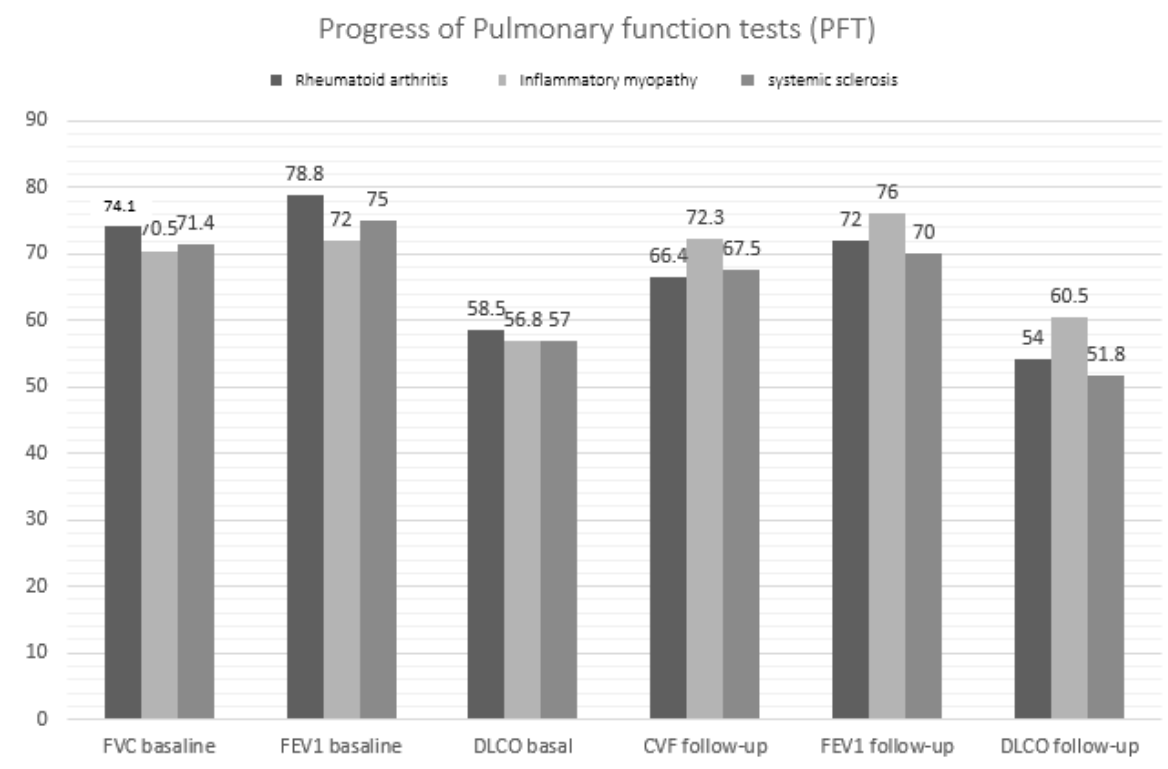

Figure 2. Changes in pulmonary function values by ILD-SAI subgroup. 
HRCT revealed disease progression in $72 / 204$ patients $(35.3 \%)$, whereas $44 / 204(21.5 \%)$ met the criteria for progression of ILD and 29/204 (14.2\%) died. Progression by HRCT was more pronounced in patients with RA and SS $(p=0.002)$. Analysis of lung disease by subgroup revealed more frequent progression and death in 48/123 (39\%), followed by $21 / 58(36 \%)$ in those with SS and $4 / 23(17 \%)$ in those with IM $(p=0.016)$. Mean survival until progression and death was 136.3 (11.0) months, with a higher median value for IM than for SS and RA (median [95\% CI], 171.7 [107.8-210.3] vs. 159.0 [137.9-174.7] vs. 111.3 [65.0-127.3] months; $p=0.017$ [log-rank]).

\subsection{Factors Associated with Progression of Lung Disease and Death in ILD-SAI}

Table 4 shows the results of the Cox multivariate analysis (dependent variable: progression or death) performed in 204 patients with ILD-SAI over a median 56.5 (29.8-93.3) months. The outcome was progression or death in $73 / 206$ patients. The multivariate analysis revealed that smoking, UIP pattern, FVC $<80 \%$ at initiation of follow-up, and diagnosis of RA vs. SS and IM were associated with a higher probability of progression of lung disease and death.

Table 4. Cox regression model (adjusted for progression of ILD).

\begin{tabular}{|c|c|c|c|}
\hline Variable & Univariate HR (95\% CI) & Multivariate HR (95\% CI) & $p$ Value \\
\hline Age, years & $1.025(1.00-1.05)$ & & \\
\hline Male sex & $1.172(0.64-2.14)$ & & \\
\hline Current or previous smoking & $2.419(1.48-3.94)$ & $2.799(1.64-4.75)$ & 0.010 \\
\hline UIP pattern & $2.317(1.44-3.71)$ & $1.787(1.06-2.99)$ & 0.028 \\
\hline Positive ACPA or scl70 values & $2.046(1.31-3.19)$ & & \\
\hline Baseline FVC $<80 \%$ & $2.840(1.47-5.48)$ & $2.348(1.40-3.92)$ & 0.015 \\
\hline Baseline DLCO-SB $<80 \%$ & $3.696(0.86-9.12)$ & & \\
\hline Corticosteroids & $1.434(0.76-2.08)$ & & \\
\hline csDMARDs & $1.080(0.595-1.96)$ & & \\
\hline Immunosuppressants & $0.937(0.52-1.66)$ & & \\
\hline bDMARDs & $0.744(0.40-1.35)$ & & \\
\hline SAI subtype & $2.101(1.20-3.66)$ & $1.901(1.32-2.73)$ & 0.027 \\
\hline
\end{tabular}

Abbreviations. RA: rheumatoid arthritis; ILD: inflammatory lung disease; UIP: usual interstitial pattern; ACPA: anticitrullinated peptide antibody; FVC: forced vital capacity; DLCO-SB: diffusing capacity of the lung for carbon monoxide (single breath); csDMARD: conventional synthetic disease-modifying antirheumatic drug; bDMARD: biologic disease-modifying antirheumatic drug; SAI: systemic autoimmune disease. Independent variables: Sex, age, smoking history, radiological pattern (UIP/nonspecific interstitial pneumonia), positive values for ACPA and anti-SCL70 antibodies, baseline FVC, baseline DLCO-SB, corticosteroids, csDMARDs (methotrexate, leflunomide, hydroxychloroquine, sulfasalazine), immunosuppressants (azathioprine, mycophenolate), bDMARDs (anti-TNF, anti-IL6, abatacept, and rituximab), SAI subtype (inflammatory myopathy, systemic sclerosis, and rheumatoid arthritis).

\section{Discussion}

We found that after 5 years' progression of the three types of ILD-SAI, ILD stabilized or improved in almost two-thirds of patients. These results are similar or even superior to those observed in other cohorts of patients with ILD-SAI [5,40-42]. This improvement is probably associated with increased use of specific immunosuppressants and biologics $[43,44]$. Furthermore, the predominance of patients with RA (followed by SS and IM) reflects the prevalence reported for each of these diseases elsewhere [45].

The poorer course of lung disease in patients with RA than in those with SS and IM $(p=0.016)$ is consistent with reports of better survival for IM and SS than other SAI in patients with ILD $[40,46,47]$, especially RA $[45,48]$. The particularly poor result for patients with RA is probably due to specific epidemiological, clinical, and radiological characteristics of this disease. Our multivariate analysis revealed that, together with the diagnosis of RA, the UIP pattern, baseline FVC $<80 \%$, and current or previous smoking were independently associated with poor pulmonary outcomes. In contrast with observations in patients with SS and IM, in whom the NSIP pattern (considered more inflammatory and less fibrosing) is predominant, the incidence of UIP, the most fibrotic subtype, is higher in HRCT [49]. The inflammatory forms generally respond better to immunosuppression than the fibrotic 
forms [42], as reflected in the different survival rates. For example, 5-year survival was $36 \%$ in patients with ILD-RA and the UIP pattern and 94\% in those with the NSIP pattern [25]. Similarly, 5-year survival in patients with SS and IM and a mainly NSIP pattern ranges from $60 \%$ to $85 \%$ [2]. Nevertheless, the HRCT pattern is not the only important one, and other authors have reported that progression of ILD-SS may not depend only on histopathology, since the 5- and 10-year survival rates in patients with a UIP or NSIP pattern in the biopsy were $82-90 \%$ and $29-69 \%$, respectively [50].

Another factor associated with poorer outcomes in ILD was smoking, which was more prevalent in patients with RA. While some studies did not show active smoking to be a risk factor for mortality or progression of ILD-SAI [15,51], others that evaluated smoking as active or previous (as in our study) did in fact find smoking to be a predictor of progression of lung disease [5]. The third factor associated with more frequent progression and mortality in our study was greater baseline impairment of FVC. Given that this factor was also observed in RA [2,11,15,51], identification of these three factors could enable more intensive therapy or earlier referral for assessment of lung transplantation.

Furthermore, as observed elsewhere, other factors may play a role and were identified only in our bivariate analysis. Thus, we observed that patients with IM and ILD responded particularly well to mycophenolate or rituximab, with fewer decreases in PFT values and more frequent stabilization of HRCT than in other ILD-SAI groups [52].

Disease-specific prognostic factors also included the greater presence of men and older patients in RA than in the other groups [53], in contrast with findings for ILDSS and ILD-IM [54]. Another difference was the variation in antibody specificity and the type of treatment received. More than $80 \%$ of patients with RA had positive RA or ACPA values, whereas those with SS and IM mainly had greater percentages of antiScl70 and antisynthetase antibodies, respectively. This observation is consistent with data reported elsewhere [2,4].

Our study is subject to a series of limitations. First, its retrospective design meant that there was no information on progression during the different periods of the course of the disease. However, clinical, laboratory, and HRCT and PFT data were available for all patients at onset and at inclusion, thus making it possible to determine progression at the end of follow-up. Furthermore, while we considered various SAIs with different pathogenic mechanisms (thus hampering identification of subtle predictors in prognosis), the main objective of our study was to know the clinical and epidemiological differences in and progression of lung disease for each of the three subgroups studied. Additionally, it is noteworthy that although the imbalance between RA and SS/IM could have hampered the analysis, the large sample size revealed sufficient differences between the subgroups. Despite these limitations, our study is one of the few that identifies epidemiologic and clinical differences, as well as differences in how progress of the various types of ILD-SAI affects the lungs, since this will provide a better picture of the progress of each group of patients and make it possible to identify patients who may require more intensive therapy or earlier referral for evaluation of lung transplant.

\section{Conclusions}

In conclusion, lung function stabilized in more than half of the patients with ILD-SAI after a median of 5 years of follow-up, although somewhat more than one-third progressed rapidly and died. Our data indicated that smoking, UIP pattern, and greater decrease in FVC at disease onset predict progression and death in patients with ILD-SAI. Furthermore, progression and mortality were worse for patients with RA than for those with SS or IM. The ability to predict which patients will progress could facilitate prognosis and early treatment. The morbidity and mortality associated with ILD-SAI make it necessary to perform more studies so that we can identify more risk factors and design models for predicting progression and mortality in ILD-SAI. 
Author Contributions: N.M.-V. was a contributor in including patients. A major contributor in writing the manuscript. She was a contributor in analyzing and interpreting the patient data. M.R.-G., C.M.R.-B. and S.M.-A. designed the data collection instruments, collected data, carried out the initial analyses, and reviewed and revised the manuscript. A.H.C., R.A.D.d.1.R., E.C.C., R.O.-C., I.A.-O., L.P.-A., M.A.-C., I.U.-G., M.L.V.-F. and R.R.-R. contributed to including patients. E.C.C., F.E. and M.C.A.-H. intervened in reviewing the lung function data and pulmonary radiology. A.F.-N. conceptualized and designed the study, coordinated, and supervised data collection and reviewed and revised the manuscript. All authors approved the final manuscript as submitted and agree to be accountable for all aspects of the work. All authors have read and agreed to the published version of the manuscript.

Funding: This research received no external funding.

Institutional Review Board Statement: The study was conducted according to the guidelines of the Declaration of Helsinki, and approved by the Research Ethics Committee of Hospital Regional Univer-sitario de Málaga (HRUM) (Code 2017-N-19).

Informed Consent Statement: Informed consent was obtained from all subjects involved in the study.

Data Availability Statement: Data presented in this study are available on request from the corresponding author.

Acknowledgments: FERBT2021- The authors thank the Spanish Foundation of Rheumatology for providing medical writing/editorial assistance during the preparation of the manuscript.

Conflicts of Interest: The authors declare no conflict of interest.

\section{References}

1. Robles-Pérez, A.; Luburich, P.; Bolivar, S.; Dorca, J.; Nolla, J.M.; Molina-Molina, M.; Narváez, J.A. A prospective study of lung disease in a cohort of early rheumatoid arthritis patients. Sci. Rep. 2020, 10, 15640. [CrossRef]

2. Demoruelle, M.K.; Mittoo, S.; Solomon, J.J. Connective tissue disease-related interstitial lung disease. Best Pract. Res. Clin. Rheumatol. 2016, 30, 39-52. [CrossRef] [PubMed]

3. Steen, V.D.; Medsger, T.A. Changes in causes of death in systemic sclerosis, 1972-2002. Ann. Rheum. Dis. 2007, 66, 940-944. [CrossRef] [PubMed]

4. Cottin, V.; Thivolet-Béjui, F.; Reynaud-Gaubert, M.; Cadranel, J.; Delaval, P.; Ternamian, P.J.; Cordier, J.F.; Groupe d'Etudes et de Recherche sur les Maladies "Orphelines" Pulmonaires. Interstitial lung disease in amyopathic dermatomyositis, dermatomyositis and polymyositis. Eur. Respir. J. 2003, 22, 245-250. [CrossRef] [PubMed]

5. Chan, C.; Ryerson, C.J.; Dunne, J.V.; Wilcox, P.G. Demographic and clinical predictors of progression and mortality in connective tissue disease-associated interstitial lung disease: A retrospective cohort study. BMC Pulm. Med. 2019, 19, 192. [CrossRef] [PubMed]

6. Mena-Vázquez, N.; Godoy-Navarrete, F.J.; Manrique-Arija, S.; Aguilar-Hurtado, M.C.; Romero-Barco, C.M.; Ureña-Garnica, I.; Espildora, F.; Añón-Oñate, I.; Pérez-Albaladejo, L.; Gomez-Cano, C.; et al. Non-anti-TNF biologic agents are associated with slower worsening of interstitial lung disease secondary to rheumatoid arthritis. Clin. Rheumatol. 2020, 40, 133-142. [CrossRef]

7. Kim, D.; Cho, S.K.; Choi, C.B.; Choe, J.Y.; Chung, W.T.; Hong, S.J.; Jun, J.B.; Jung, Y.O.; Kim, T.H.; Kim, T.J.; et al. Impact of interstitial lung disease on mortality of patients with rheumatoid arthritis. Rheumatol. Int. 2017, 37, 1735-1745. [CrossRef]

8. Hyldgaard, C.; Hilberg, O.; Pedersen, A.B.; Ulrichsen, S.P.; Løkke, A.; Bendstrup, E.; Ellingsen, T. A population-based cohort study of rheumatoid arthritis-associated interstitial lung disease: Comorbidity and mortality. Ann. Rheum. Dis. 2017, 76, 1700-1706. [CrossRef]

9. Koduri, G.; Norton, S.; Young, A.; Cox, N.; Davies, P.; Devlin, J.; Dixey, J.; Gough, A.; Prouse, P.; Winfield, J.; et al. ERAS (Early Rheumatoid Arthritis Study). Interstitial lung disease has a poor prognosis in rheumatoid arthritis: Results from an inception cohort. Rheumatology 2010, 49, 1483-1489. [CrossRef]

10. Kakutani, T.; Hashimoto, A.; Tominaga, A.; Kodama, K.; Nogi, S.; Tsuno, H.; Ogihara, H.; Nunokawa, T.; Komiya, A.; Furukawa, H.; et al. Related factors, increased mortality and causes of death in patients with rheumatoid arthritis-associated interstitial lung disease. Mod. Rheumatol. 2020, 30, 458-464. [CrossRef]

11. Solomon, J.J.; Ryu, J.H.; Tazelaar, H.D.; Myers, J.L.; Tuder, R.; Cool, C.D.; Curran-Everett, D.; Fischer, A.; Swigris, J.J.; Brown, K.K. Fibrosing interstitial pneumonia predicts survival in patients with rheumatoid arthritis-associated interstitial lung disease (RA-ILD). Respir. Med. 2013, 107, 1247-1252. [CrossRef]

12. Yang, J.A.; Lee, J.S.; Park, J.K.; Lee, E.B.; Song, Y.W.; Lee, E.Y. Clinical characteristics associated with occurrence and poor prognosis of interstitial lung disease in rheumatoid arthritis. Korean. J. Intern. Med. 2019, 34, 434-441. [CrossRef]

13. Kim, E.J.; Elicker, B.M.; Maldonado, F.; Webb, W.R.; Ryu, J.H.; Van Uden, J.H.; Lee, J.S.; King, T.E., Jr.; Collard, H.R. Usual interstitial pneumonia in rheumatoid arthritis-associated interstitial lung disease. Eur. Respir. J. 2010, 35, 1322-1328. [CrossRef] 
14. Kim, H.C.; Choi, K.H.; Jacob, J.; Song, J.W. Prognostic role of blood KL-6 in rheumatoid arthritis-associated interstitial lung disease. PLoS ONE 2020, 15, e0229997. [CrossRef]

15. Winstone, T.A.; Assayag, D.; Wilcox, P.G.; Dunne, J.V.; Hague, C.J.; Leipsic, J.; Collard, H.R.; Ryerson, C.J. Predictors of mortality and progression in scleroderma-associated interstitial lung disease: A systematic review. Chest 2014, 146, 422-436. [CrossRef]

16. Singh, N.; Varghese, J.; England, B.R.; Solomon, J.J.; Michaud, K.; Mikuls, T.R.; Healy, H.S.; Kimpston, E.M.; Schweizer, M.L. Impact of the pattern of interstitial lung disease on mortality in rheumatoid arthritis: A systematic literature review and meta-analysis. Semin. Arthritis Rheum. 2019, 49, 358-365. [CrossRef]

17. Zamora-Legoff, J.A.; Krause, M.L.; Crowson, C.S.; Ryu, J.H.; Matteson, E.L. Patterns of interstitial lung disease and mortality in rheumatoid arthritis. Rheumatology 2017, 56, 344-350. [CrossRef] [PubMed]

18. Fu, Q.; Wang, L.; Li, L.; Li, Y.; Liu, R.; Zheng, Y. Risk factors for progression and prognosis of rheumatoid arthritis-associated interstitial lung disease: Single center study with a large sample of Chinese population. Clin. Rheumatol. 2019, 38, 1109-1116. [CrossRef]

19. Hozumi, H.; Nakamura, Y.; Johkoh, T.; Sumikawa, H.; Colby, T.V.; Kono, M.; Hashimoto, D.; Enomoto, N.; Fujisawa, T.; Inui, N.; et al. Acute exacerbation in rheumatoid arthritis-associated interstitial lung disease: A retrospective case control study. BMJ Open 2013, 3, e003132. [CrossRef] [PubMed]

20. Jacob, J.; Song, J.W.; Yoon, H.Y.; Cross, G.; Barnett, J.; Woo, W.L.; Adams, F.; Kokosi, M.; Devaraj, A.; Renzoni, E.; et al. Prevalence and Effects of Emphysema in Never-Smokers with Rheumatoid Arthritis Interstitial Lung Disease. EBioMedicine 2018, 28 , 303-310. [CrossRef] [PubMed]

21. Lee, H.K.; Kim, D.S.; Yoo, B.; Seo, J.B.; Rho, J.Y.; Colby, T.V.; Kitaichi, M. Histopathologic pattern and clinical features of rheumatoid arthritis-associated interstitial lung disease. Chest 2005, 127, 2019-2027. [CrossRef] [PubMed]

22. Nurmi, H.M.; Purokivi, M.K.; Kärkkäinen, M.S.; Kettunen, H.-P.; Selander, T.A.; Kaarteenaho, R.L. Variable course of disease of rheumatoid arthritis-associated usual interstitial pneumonia compared to other subtypes. BMC Pulm. Med. 2016, 16, 107. [CrossRef]

23. Rojas-Serrano, J.; Herrera-Bringas, D.; Pérez-Román, D.I.; Pérez-Dorame, R.; Mateos-Toledo, H.; Mejía, M. Rheumatoid arthritisrelated interstitial lung disease (RA-ILD): Methotrexate and the severity of lung disease are associated to prognosis. Clin. Rheumatol. 2017, 36, 1493-1500. [CrossRef]

24. Solomon, J.J.; Chung, J.H.; Cosgrove, G.P.; Demoruelle, M.K.; Fernandez-Perez, E.R.; Fischer, A.; Frankel, S.K.; Hobbs, S.B.; Huie, T.J.; Ketzer, J.; et al. Predictors of mortality in rheumatoid arthritis-associated interstitial lung disease. Eur. Respir. J. 2016, 47, 588-596. [CrossRef] [PubMed]

25. Tsuchiya, Y.; Takayanagi, N.; Sugiura, H.; Miyahara, Y.; Tokunaga, D.; Kawabata, Y.; Sugita, Y. Lung diseases directly associated with rheumatoid arthritis and their relationship to outcome. Eur. Respir. J. 2011, 37, 1411-1417. [CrossRef] [PubMed]

26. Morisset, J.; Vittinghoff, E.; Lee, B.Y.; Tonelli, R.; Hu, X.; Elicker, B.M.; Ryu, J.H.; Jones, K.D.; Cerri, S.; Manfredi, A.; et al. The performance of the GAP model in patients with rheumatoid arthritis associated interstitial lung disease. Respir. Med. 2017, 127, 51-56. [CrossRef]

27. Distler, O.; Brown, K.K.; Distler, J.H.W.; Assassi, S.; Maher, T.M.; Cottin, V.; Varga, J.; Coeck, C.; Gahlemann, M.; Sauter, W.; et al. Design of a randomised, placebo-controlled clinical trial of nintedanib in patients with systemic sclerosis-associated interstitial lung disease (SENSCIS ${ }^{\mathrm{TM}}$ ). Clin. Exp. Rheumatol. 2017, 35 (Suppl. 106), 75-81.

28. Flaherty, K.R.; Wells, A.U.; Cottin, V.; Devaraj, A.; Walsh, S.L.F.; Inoue, Y.; Richeldi, L.; Kolb, M.; Tetzlaff, K.; Stowasser, S.; et al. Nintedanib in Progressive Fibrosing Interstitial Lung Diseases. N. Engl. J. Med. 2019, 381, 1718-1727. [CrossRef]

29. Narváez, J.; Robles-Pérez, A.; Molina-Molina, M.; Vicens-Zygmunt, V.; Luburich, P.; Yañez, M.A.; Alegre, J.J.; Nolla, J.M. Realworld clinical effectiveness of rituximab rescue therapy in patients with progressive rheumatoid arthritis-related interstitial lung disease. Semin. Arthritis Rheum. 2020, 50, 902-910. [CrossRef]

30. Md Yusof, M.Y.; Kabia, A.; Darby, M.; Lettieri, G.; Beirne, P.; Vital, E.M.; Dass, S.; Emery, P. Effect of rituximab on the progression of rheumatoid arthritis-related interstitial lung disease: 10 years' experience at a single centre. Rheumatology 2017, 56, 1348-1357. [CrossRef]

31. Fernández-Díaz, C.; Loricera, J.; Castañeda, S.; López-Mejías, R.; Ojeda-García, C.; Olivé, A.; Rodríguez-Muguruza, S.; Carreira, P.E.; Pérez-Sandoval, T.; Retuerto, M.; et al. Abatacept in patients with rheumatoid arthritis and interstitial lung disease: A national multicenter study of 63 patients. Semin. Arthritis Rheum. 2018, 48, 22-27. [CrossRef]

32. Fernández-Díaz, C.; Castañeda, S.; Melero-González, R.B.; Ortiz-Sanjuán, F.; Juan-Mas, A.; Carrasco-Cubero, C.; Casafont-Solé, I.; Olivé, A.; Rodríguez-Muguruza, S.; Almodóvar-González, R.; et al. Abatacept in interstitial lung disease associated with rheumatoid arthritis: National multicenter study of 263 patients. Rheumatology 2020, 59, 3906-3916. [CrossRef] [PubMed]

33. Manfredi, A.; Cassone, G.; Furini, F.; Gremese, E.; Venerito, V.; Atzeni, F.; Arrigoni, E.; Della Casa, G.; Cerri, S.; Govoni, M.; et al. Tocilizumab therapy in rheumatoid arthritis with interstitial lung disease: A multicenter retrospective study. Intern. Med. J. 2019, 50, 1085-1090. [CrossRef] [PubMed]

34. Bosello, S.L.; De Luca, G.; Rucco, M.; Berardi, G.; Falcione, M.; Danza, F.M.; Pirronti, T.; Ferraccioli, G. Long-term efficacy of B cell depletion therapy on lung and skin involvement in diffuse systemic sclerosis. Semin. Arthritis Rheum. 2015, 44, 428-436. [CrossRef] [PubMed]

35. Marie, I.; Dominique, S.; Janvresse, A.; Levesque, H.; Menard, J.F. Rituximab therapy for refractory interstitial lung disease related to antisynthetase syndrome. Respir. Med. 2012, 106, 581-587. [CrossRef] 
36. Aletaha, D.; Neogi, T.; Silman, A.J.; Funovits, J.; Felson, D.T.; Bingham, C.O., 3rd; Birnbaum, N.S.; Burmester, G.R.; Bykerk, V.P.; Cohen, M.D.; et al. 2010 Rheumatoid arthritis classification criteria: An American College of Rheumatology/European League Against Rheumatism collaborative initiative. Arthritis Rheum. 2010, 62, 2569-2581. [CrossRef] [PubMed]

37. Bohan, A.; Peter, J.B. Polymyositis and dermatomyositis (first of two parts). N. Engl. J. Med. 1975, 292, 344-347. [CrossRef]

38. Bohan, A.; Peter, J.B. Polymyositis and dermatomyositis (second of two parts). N. Engl. J. Med. 1975, 292, 403-407. [CrossRef]

39. Travis, W.D.; Costabel, U.; Hansell, D.M.; King, T.E.; Lynch, D.A., Jr.; Nicholson, A.G.; Ryerson, C.J.; Ryu, J.H.; Selman, M.; Wells, A.U.; et al. An official American Thoracic Society/European Respiratory Society statement: Update of the international multidisciplinary classification of the idiopathic interstitial pneumonias. Am. J. Respir. Crit. Care Med. 2013, 188, 733-748. [CrossRef]

40. Su, R.; Bennett, M.; Jacobs, S.; Hunter, T.; Bailey, C.; Krishnan, E.; Rosen, G.; Chung, L. An analysis of connective tissue diseaseassociated interstitial lung disease at a US Tertiary Care Center: Better survival in patients with systemic sclerosis. J. Rheumatol. 2011, 38, 693-701. [CrossRef]

41. Jacob, J.; Bartholmai, B.J.; Rajagopalan, S.; Brun, A.L.; Egashira, R.; Karwoski, R.; Kokosi, M.; Wells, A.U.; Hansell, D.M. Evaluation of computer-based computer tomography stratification against outcome models in connective tissue disease-related interstitial lung disease: A patient outcome study. BMC Med. 2016, 14, 190. [CrossRef] [PubMed]

42. Park, J.H.; Kim, D.S.; Park, I.N.; Jang, S.J.; Kitaichi, M.; Nicholson, A.G.; Colby, T.V. Prognosis of fibrotic interstitial pneumonia: Idiopathic versus collagen vascular disease-related subtypes. Am. J. Respir. Crit. Care Med. 2007, 175, 705-711. [CrossRef] [PubMed]

43. Kelly, C.A.; Nisar, M.; Arthanari, S.; Carty, S.; Woodhead, F.A.; Price-Forbes, A.; Middleton, D.; Dempsey, O.; Miller, D.; Basu, N.; et al. Rheumatoid arthritis related interstitial lung disease-improving outcomes over 25 years: A large multicentre UK study. Rheumatology 2020, 60, 1882-1890. [CrossRef]

44. Mena-Vázquez, N.; Rojas-Gimenez, M.; Romero-Barco, C.M.; Manrique-Arija, S.; Francisco, E.; Aguilar-Hurtado, M.C.; Añón-Oñate, I.; Pérez-Albaladejo, L.; Ortega-Castro, R.; Godoy-Navarrete, F.J.; et al. Predictors of Progression and Mortality in Patients with Prevalent Rheumatoid Arthritis and Interstitial Lung Disease: A Prospective Cohort Study. J. Clin. Med. 2021, 10, 874. [CrossRef] [PubMed]

45. Wallace, B.; Vummidi, D.; Khanna, D. Management of connective tissue diseases associated interstitial lung disease: A review of the published literature. Curr. Opin. Rheumatol. 2016, 28, 236-245. [CrossRef]

46. Navaratnam, V.; Ali, N.; Smith, C.J.; McKeever, T.; Fogarty, A.; Hubbard, R.B. Does the presence of connective tissue disease modify survival in patients with pulmonary fibrosis? Respir. Med. 2011, 105, 1925-1930. [CrossRef] [PubMed]

47. Moua, T.; Zamora Martinez, A.C.; Baqir, M.; Vassallo, R.; Limper, A.H.; Ryu, J.H. Predictors of diagnosis and survival in idiopathic pulmonary fibrosis and connective tissue disease-related usual interstitial pneumonia. Respir. Res. 2014, 15, 154. [CrossRef] [PubMed]

48. Nurmi, H.M.; Purokivi, M.K.; Kärkkäinen, M.S.; Kettunen, H.P.; Selander, T.A.; Kaarteenaho, R.L. Are risk predicting models useful for estimating survival of patients with rheumatoid arthritis-associated interstitial lung disease? BMC Pulm. Med. 2017, 17, 16. [CrossRef]

49. Yıldırım, F.; Türk, M.; Bitik, B.; Erbaş, G.; Köktürk, N.; Haznedaroğlu, Ş.; Türktaş, H. Comparison of clinical courses and mortality of connective tissue disease-associated interstitial pneumonias and chronic fibrosing idiopathic interstitial pneumonias. Kaohsiung J. Med. Sci. 2019, 35, 365-372. [CrossRef]

50. Bouros, D.; Wells, A.U.; Nicholson, A.G.; Colby, T.V.; Polychronopoulos, V.; Pantelidis, P.; Haslam, P.L.; Vassilakis, D.A.; Black, C.M.; du Bois, R.M. Histopathologic subsets of fibrosing alveolitis in patients with systemic sclerosis and their relationship to outcome. Am. J. Respir. Crit. Care Med. 2002, 165, 1581-1586. [CrossRef]

51. Reiseter, S.; Gunnarsson, R.; Mogens Aaløkken, T.; Lund, M.B.; Mynarek, G.; Corander, J.; Haydon, J.; Molberg, Ø. Progression and mortality of interstitial lung disease in mixed connective tissue disease: A long-term observational nationwide cohort study. Rheumatology 2018, 57, 255-262. [CrossRef]

52. Sharp, C.; McCabe, M.; Dodds, N.; Edey, A.; Mayers, L.; Adamali, H.; Millar, A.B.; Gunawardena, H. Rituximab in autoimmune connective tissue disease-associated interstitial lung disease. Rheumatology 2016, 55, 1318-1324. [CrossRef]

53. Solomon, J.J.; Brown, K.K. Rheumatoid arthritis-associated interstitial lung disease. Open Access Rheumatol. $2012,4,21-31$. [PubMed]

54. McNearney, T.A.; Reveille, J.D.; Fischbach, M.; Friedman, A.W.; Lisse, J.R.; Goel, N.; Tan, F.K.; Zhou, X.; Ahn, C.; Feghali-Bostwick, C.A.; et al. Pulmonary involvement in systemic sclerosis: Associations with genetic, serologic, sociodemographic, and behavioral factors. Arthritis Rheum. 2007, 57, 318-326. [CrossRef] [PubMed] 